\title{
INDIGENOUS KNOWLEDGE AND PRACTICES IN THE CONTROL OF RABIES IN NORTH CENTRAL NIGERIA
}

\author{
AIYEDUN J.O. ${ }^{1}$; OLUDAIRO O.O. ${ }^{1}$ and OLORUNSHOLA I.D. ${ }^{2}$ \\ ${ }^{1}$ Department of Veterinary Public Health and Preventive Medicine, Faculty of Veterinary \\ Medicine, University of Ilorin, Nigeria \\ ${ }^{2}$ Department of Veterinary Microbiology, Faculty of Veterinary Medicine, University of Ilorin, Nigeria.
}

Received: 12 February 2017; Accepted: 2 March 2017

\begin{abstract}
This study was carried out to access the indigenous and practical knowledge about rabies control in Ifelodun and Irepodun Local Government Areas (LGA) of Kwara State, Nigeria. Our investigations combined literature review, focus group discussion and in-depth interview. Information obtained from 246 adults revealed that $65 \%$ of the respondents keep dogs for hunting and security, while the remaining 35\% do not keep dogs. Local farmers and hunters who kept dogs claimed that rabid dogs and their human victims are curable with local herbs such as "Apa - asa", "imi- esu", goat weeds, raw walnut, fresh okro and materials such as "Adin-eyan", salt, cobra intestine, dog's blood, dog's hair, and "aporoepaijebu" which were either applied topically on the wound or taken orally by the victim immediately after the bite. It was observed that the respondents had limited knowledge about the dumb form of rabies compared with the furious type (locally referred to as 'Digbolugi'). Our data analysis showed that goat weeds 62(25.2\%), Apa - asa 53(21.5\%) Adin-eyan and salt 82(33.3\%), combination of Dog's blood and hair 74(30.1) were the range of efficacious herbs and materials used to treat rabies in those communities. Poverty and ignorance still poses challenges in the use of veterinary services by the farmers in most communities in Nigeria. Hence, the needs for the government's interventions for affordable veterinary services, organising campaigns on rabies vaccination, funding research on these local remedies as well as incorporating ethinovetrinary practices in the curriculum of learning in Nigeria.
\end{abstract}

Key words: Indigenous knowledge and practices, Control, Rabies, North Central Nigeria

\section{INTRODUCTION}

Indigenous knowledge and practices has existed since pre-historic times and flourishes today as the primary form of human and animal medicine, more than $80 \%$ of the world's population, mostly in poor and less-developed countries, depend on traditional medicine for their primary health care requirements (WHO, 1993, Bajaj and Williams, 1995).Although the evolution and development of ethno veterinary medicines have lagged behind that of human (Kofi-Tsekpo and Kioy 1998; Schillborn van Veen 1997). Today, ethno veterinary medicine remains an ethno scientific resource that is yet to be tapped and has a far-reaching implication on the economic development and enhancement of veterinary health particularly rural poor communities, which do not have access to modern veterinary and medical services (Lans, 2001). However, the aim of this study is to identify the beneficial and appropriate

Corresponding author: Dr. OLUDAIRO O. O.

E-mail address: olaaiyedun@yahoo.com; oludairo@hotmail.com

Present address: Department of Veterinary Public Health and Preventive Medicine, Faculty of Veterinary Medicine, University of Ilorin, Nigeria ethno veterinary interventions used to control rabies. There is need also to facilitate a multilateral dialogue between local communities and governments with the ultimate objective of mainstreaming indigenous/ traditional knowledge in the control of rabies in Nigeria.

Indigenous knowledge and practices which were once considered as witchcraft, poor man's affair, sinful and out-dated have currently emerged as 'very fertile fields' that are really promising to benefit the entire population in the world (McCorkle, 1998). This realization comes in the wake of tough economic times and the present global down turn in the world economy. In this situation therefore, traditional medicine offers the best alternative, particularly to world poorest rural areas.

Rabies is the oldest communicable disease of humans (Wilkinson, 1988). Recognition of the disease dates back to the 23rd Century BC, from which pre-Mosaic Eshmuna Code of Babylon was found describing a disease in dogs that was lethal in man if bitten (Baer et al., 1996). Rabies comes from the Latin word 'rabere,' which means 'to rage' or 'to rave'. This 
Latin word may have roots in a Sanskrit word 'rabhas, ' which means 'to do violence'. The Greeks called rabies 'lyssa' or 'lytta,' which means frenzy or madness. They named human rabies 'hydrophobia,' which means 'fear of water,' a symptom shown by rabies victims (A Rabies-free World Inc., 2008). Rabies is present in all continents and is endemic in most African and Asian countries (WHO, 2008).

Rabies is an acute encephalomyelitis that affects all warm-blooded wild and domestic animals and humans, and is almost always fatal once symptoms occur (CDC, 2008; WHO, 2008). It is caused by a neurotropic RNA virus, which belongs to the genus Lyssavirus of the family Rhabdoviridae, and is found mostly in the brain, spinal cord, salivary glands, and saliva of the affected animals (McElhinney et al., 2008). Wild animals are reservoirs of the virus and they transmit the disease usually through bite and virus-rich saliva. Transmission by non-salivary routes has been recorded (Milius et al., 2004). These include aerosol transmission to humans in the laboratory and in bat-infested caves. Most often, humans contract the disease from stray domestic animals. However, animals contract the disease through wounds, when they are bitten by another animal infected with rabies. Most dangerous wounds are those close to the head or wounds that do not bleed. The incubation period is prolonged and highly variable, depending on the quantity of the inoculum and the site of the bite, being shorter after a bite near the brain than following a more distant one (Zienius et al., 2003; Milius et al., 2004).

Rabies has been eliminated as a significant public health risk in most parts of the developed world. However, it is estimated to cause at least 60,000100,000 deaths per year worldwide, classified as the eleventh killer disease of the world, majority of which occur in Asia and Africa, particularly in rural areas in both continents (Tang et al., 2005; WHO, 2008). Although post-exposure prophylaxis using modern vaccines and when appropriate, rabies immunoglobulin is effective in most situations (WHO 2008). People still die of rabies, mainly children that do not receive the necessary rabies immunoglobulin because it is either unavailable or unaffordable in countries where rabies is endemic (WHO, 2008). Therefore, alternative remedy ought to be sought to meet the urgent need within the community in sub sahara Africa especially in Nigeria.

The acceptance and appreciation by the western world, of the fact that some indigenous traditional practices and knowledge regarding natural substances of plant origin have been, and still are, used by different societies throughout the world to kill or repel aetiological agents of diseases in man and animals has further, made it possible for the renewed interests in this subject (Schillhorn van Veen 1997). It is now realized that this kind of complementary medical approach is crucial and necessary to improve animal and human health at community level (Toyang et al., 1995).

\section{Historical perspective of Rabies}

Rabies is one of the oldest documented diseases of humans. Ancient writers in Mesopotamia, China, Greece, Rome, and India described classic symptoms that have both intrigued physicians and terrified the public for millennia (Patterson, 1993). There have been claims of rabies from the times of Homer at about 8th Century BC (Neville, 2004). In the first century AD, Aulus Cornelius Celsus prescribed a cure for rabies by dunking the patient in a pool (Kaplan and Meslin, 1996). Rabies has been associated with animal bites for more than 3000 years and it is the oldest infectious disease known to medical science (Wilkinson, 1988). Dogs have long been recognized as the main transmitters of the disease to man (King and Turner, 1993). When compared with other formidable human diseases, such as bubonic plague and smallpox, and animal diseases such as rinderpest and anthrax, rabies has probably never caused comparatively high number of deaths in humans and animals. However, the horrendous manner in which rabies manifests itself in its victims continues to attract the attention of scientists, traditionalist, health and veterinary workers (Bishop et al., 2003). Rabies was considered to be transmitted by the frenulum of infected dogs. This led to the treatment of clinical rabies by cutting the frenulum of the suspected dog in which the rabies worm was felt to reside, and applying it to the infected victim (Ratzan, 2006).

Emphasis of governments and non-governmental agencies in Africa is mainly focused on human immunodeficiency syndrome (HIV/AIDS), poliomyelitis, tuberculosis and malaria, yet rabies constitute much greater health challenge and economic burden in Africa than imagined (Cleaveland et al., 2007).

The greatest challenge to rabies control worldwide is the extent of the dog rabies epizootics in Asia and Africa, about $98 \%$ of human rabies occurs in this region with large number of stray and domestic dogs (Warrel and Warrel, 2004). High prevalence of human rabies has always correlated well with stray dog population (Wilsmore et al., 2006). Efforts to eliminate such stray dogs in order to control dogmediated rabies have often been unsuccessful. This is because the so-called stray or feral dogs are often owned by an individual or group who fail to control them (Wilsmore et al., 2006).

In Nigeria, rabies in humans was first reported in 1912, while the first cases of canine rabies were documented in 1925 (Bougler and Hardy, 1960). Rabies in dogs is an endemic and widespread disease in Nigeria (Nawathe et al., 1981). It accounts for a 
considerable number of human deaths per year (Ogunkoya et al., 1984; Okonko et al., 2010) and is a source of profound fear and apprehension to man.

\section{MATERIALS AND METHODS}

A semi-structured open-ended questionnaire was developed to assess the indigenous knowledge and practices for rabies control in Ifelodun and Irepodun Local Government Areas of Kwara State, northcentral Nigeria. The focus of the questionnaire was to identify indigenous knowledge, considered important for control of rabies. Key information asked included; listing and ranking the common herbs and materials being used against rabies in animals and humans by the indigenous people in the study area. How the disease is transmitted, the most at-risk animal as far as rabies is concerned and the associated signs of disease in man and animal.

\section{Data Analysis}

The data generated from the questionnaires administered to the respondents were stored and analysed using Epi Info software package version 6.04 (Centers for Disease Control and Prevention, Atlanta, GA). The relationships between dependent and independent variables were exposed to Chi-Squre $(\chi 2)$ analysis. A P-value of $\leq 0.05$ was obtained from the analysis which shows that the use of some herbs and concursions may be very good remedies for rabies control as shown in Tables 1 and 2 .

\section{RESULTS}

246 (78\% male, 22\% female) adults, aged 40-60 years, participated in this survey. All the respondents were aware that rabies ('Digbolugi') could be transmitted through dog bite. $65 \%$ of the respondents keep dogs for hunting and security while the remaining 35\% do not keep dogs. The most common herbs (Apa - asa, imi- esu, goat weeds, raw walnut, fresh okro) and materials (adin-eyan, salt, cobra intestine, dog's blood, dog's hair, aporoepaijebu) used by the respondents from Ifelodun and Irepodun LGA of Kwara State, Nigeria are as displayed in Tables 1 and 2.

Table1: Herbs used in the control of rabies.

\begin{tabular}{ccc}
\hline & Herbs used in the control of rabies & \\
\hline Type of Herbs & Frequency & Percentage (\%) \\
\hline Apa - asa & 53 & 21.5 \\
\hline Imi- esu & 48 & 19.5 \\
\hline Goat weeds & 62 & 25.2 \\
\hline Raw walnut & 39 & 15.9 \\
\hline Fresh okro & 44 & 17.9 \\
\hline Total & 246 & 100 \\
\hline
\end{tabular}

Table2: Materials used in the control of rabies.

\begin{tabular}{ccc}
\hline \multicolumn{3}{c}{ Materials used in the control of rabies } \\
\hline Type of Material & Frequency & Percentage $(\%)$ \\
\hline Adin-eyan and salt & 82 & 33.3 \\
\hline Cobra intestine & 41 & 16.7 \\
\hline Dog's blood and hair & 74 & 30.1 \\
\hline Aporoepaijebu & 49 & 19.9 \\
\hline Total & 246 & 100 \\
\hline
\end{tabular}

This study was carried out to access the indigenous and practical knowledge about rabies, control in Ifelodun and Irepodun LGA of Kwara State, Nigeria, using the combination of literature review, questionnaires, focus group discussion and in-depth interview, information was obtained from 246 adults aged $40-60$ years ( $78 \%$ male, $22 \%$ female).

All the respondents were aware that rabies could be transmitted through dog bite, they were all conversant with the local name 'Digbolugi' and were all only aware of the furious form of rabies (typical mad dogs). Sixty five percent of the repondents keep dogs for hunting and security while the remaining $35 \%$ do not keep dogs. Local farmers and hunters who kept dogs claimed that rabid dogs and their human victims are curable with local herbs such as "Apa - asa", "imi- esu", goat weeds, raw walnut, fresh okro and materials such as "Adin-eyan", salt, cobra intestine, dog's blood, dog's hair, "aporoepaijebu" which were either applied topically on the wound or taken orally by the victim immediately after the bite. Almost all the respondents claimed that the local remedies investigated are efficacious. However, these claims are not evidenced-based submission. It is important for indigenous people to be properly educated on rabies, its control and available veterinary services. 


\section{DISCUSSION}

The respondents are not fully aware of the dumb form of rabies which could also be deadly as its circumstances of bite is quite different from the furious form. These communities therefore need information, communication and education on the dumb form of rabies.

Sixty five percent $(65 \%)$ of the respondents keep dogs for hunting and security while the remaining $35 \%$ do not keep dogs. Since more people relate closely with dogs in these communities there might be need for an expansion in the veterinary services including dog vaccinations, creating awareness on the risks associated with stray dogs, proper dog management and dangers of children's exposures to furious or dumb forms of rabies at home or on the farms.

Although the local farmers and hunters, claimed that rabid dogs and their human victims are curable with local herbs and materials as listed in Tables 1 and 2, but this is still subject to scientific investigations. In the light of this, further research could also be carried out on the herbs (Apa - asa, imi- esu, goat weeds, raw walnut, fresh okro) and the materials (adin-eyan, salt, cobra intestine, dog's blood, dog's hair, aporoepaijebu) to ascertain their active ingredients and their level of efficacy.

Based on the result as indicated in Table 1, goat weeds $62(25.2 \%)$ and Apa - asa $53(21.5 \%)$ are the most frequently used herbs by the indigenous people in the study areas as remedies for rabies management. While the most common combination of materials used by these communities are Adin-eyan and salt $82(33.3 \%)$ and Dog's blood and hair 74(30.1). There is need for scientific authentication of these herbs for the purposes of indigenous knowledge transfer to those that may be in need of it. Research priorities could be focused on these herbs and materials for their potencies. There may be needs to also include a botanist in the LGA's Veterinary Team for easy identification of some of these trees and plants which are being used for ethno veterinary medicine.

\section{CONCLUSION}

Rabies currently constitute a global threats due to its resurgence in most parts of the world. It is an important disease that has been recognized for centuries. Inappropriate and under-utilization of antirabies vaccines, low level of public health awareness, lack of nationwide animal rabies surveillance and poor attention and resource allocation by the government remained the major problems that hindered the control of rabies in Nigeria. Poverty still poses challenges in the use of veterinary services by the farmers in most communities, hence, the urgent needs for government's interventions such as subsidies on rabies vaccines and veterinary services.

\section{REFERENCES}

A Rabies-Free World Inc., (2008): How did rabies get its name? A short history of rabies. (www.worldrabiesday.org/assets/files/WRDABM-AUG08. pdf accessed on 13 October 2009). A

Baer, G.M.; Neville, J. and Turner, G.S. (1996): Rabbis and Rabies: A Pictorial History through the Ages. Mexico City: Laboratories Baer.

Bajaj, M. and Williams, J T. (1995): Healing Forests Healing People. IDRC Medicinal Plants Network, New Delhi, India.

Bougler, I.R. and Hardy, J. (1960): Rabies in Nigeria. West African Medical Journal. 9; 223-234.

Cleaveland, S. (1998): Epidemiology and control of rabies. The growing problem of rabies in Africa. Transactions of the Royal Society of Tropical Medicine and Hygiene. 92; 131-134.

Center for Disease Control and Prevention (2008): Human Rabies Prevention - United States, 2008. Recommendations of the Advisory Committee on Immunization Practices. Morbidity Mortality Weekly Report. 57; 205210.

Knobel, D.L.; Cleaveland, S.; Coleman, P.G.; Fevre, E.M.; Meltzer, M.I.; Miranda, M.E.G.; Shaw, A.; Zinsstag, J. and Meslin, F.X. (2005): Reevaluating the burden of rabies in Africa and Asia. Bulletin of World Health Organization. 83(5); 360-368.

Ratzan, R.M. (2006): Rabies in Israel 2006: An Update and Review. Israel Journal of Emergency Medicine. 6 (3); 6-26.

Schillhorn van Veen, T.W. (1997): Sense or nonsense? Traditional methods of animal parasitic disease control. Veterinary Parasitology 71: 177-194.

Lans, C. (2001): Creole Remedies. Case studies of ethnoveterinary medicine in Trinidad and Tobago. PhD Thesis, University of Wageningen, The Netherlands.

Milius, J.; Jacevicius, E.; Tamosiunas, $V$. ; Paulauskas, $\quad V$. and Lukauskas, $K$. (2004):Rabies among Wild and Domestic Animals in Lithuania In 1993-2002: Epizootiology, Diagnosis And Vaccination. Bulletin of Veterinary Institute Pulawy 48; 195-200.

Nawathe, D.R.; Banerjee, J.; Okeke, E.N. and Tiyagnet, J.N. (1981): Production and use of avianised rabies vaccine in Nigeria. International Journal of Zoonoses. 8; 1-4.

Neville, J. (2004): Rabies in the Ancient World. In: Historical Perspective of rabies in Europe and 
the Mediterranean basin. (Eds), A.A. King, A.R. Fooks, M. Aubert and A.I. Wandeler. Paris, OIE: 12.

Patterson, K.D. (1993): Rabies, in Kiple K.F (The Cambridge World History of Human Disease. Cambridge, Mass, Cambridge University Press, pg. 962-967.

Okonko, I.O.; Adedeji, O.B.; Babalola, E.T.; Fajobi, E.; Fowotade, A. and Adewale, O.G. (2010): Why is their still rabies in the world? An Emerging Microbial and Global Health Threat. Global Veterinarian 4 (1); 34-50.

Ogunkoya, A.B.; Will, A.L. and Ezeokoli, C.D. (1984): Rabies in Oyo State in Nigeria: 1971 1982. International Journal of Zoonoses. 11:84-94.

Kofi - Tsekpo, W.M. and Kioy, W.D. (1998): Newer direction of plant drug research: The need to examine and investigate traditional remedies for pharmacotheraphy of animal and zoonotic diseases. African Journal of Health Sciences 5: 12.

Toyang, N.J.; Nuwanyakpa, M.; Ndi, C.; Django, S. and Kinyuy, C.W. (1995):Ethnoveterinary medicine practices in the northwest province of Cameroon. Indigenous Knowledge and Development Monitor 3(3): 20-22.

WHO, IUCN and WWF (1993): Guidelines on the Conservation of Medicinal Plants. IUCN, Gland, Switzerland.
McCorkle, C.M. (1986): An Introduction to Ethnoveterinary Research and Development. Journal of Ethnobiology 6 (1): 129-149.

Wilkinson, L. (1988): Introduction, in Rabies. Edited by J.B. Campbell and K.M. Charlton. Boston: Kluwer Academic Publishers: 1-23.

WHO (2002): Traditional Medicine Strategy 20022005. WHO Geneva Swizerland.

Warrell, M.J. and Warrell, D.A. (2004): Rabies and other lyssavirus diseases. Lancet. 363; 959969.

Wilsmore, T.; Hamblin, C.; Taylor, N.; Taylor, W. and Watson, B. (2006): Qualitative Veterinary Risk Assessment of the Introduction of Rabies into the United Kingdom. A report prepared for the Department for Environment, Food and Rural Affairs (Defra).

World Health Organization (2008a): Rabies. Zoonosis and Veterinary Public Health.World Health Organization, 2008.

World Health Organization (2008a): Rabies. Zoonosis and Veterinary Public Health. World Health Organization, 2008.

WHO (2011): The World Medicines Situation. Traditional Medicines: Global Situation, Issues and Challenges. WHO Geneva Swizerland.

Zienius, D.; Bagdonas, J. and Dranseika, A. (2003): Epidemiological situation of rabies in Lithuania from 1990 to 2000. Veterinary Microbiology. 93, 91-100. 